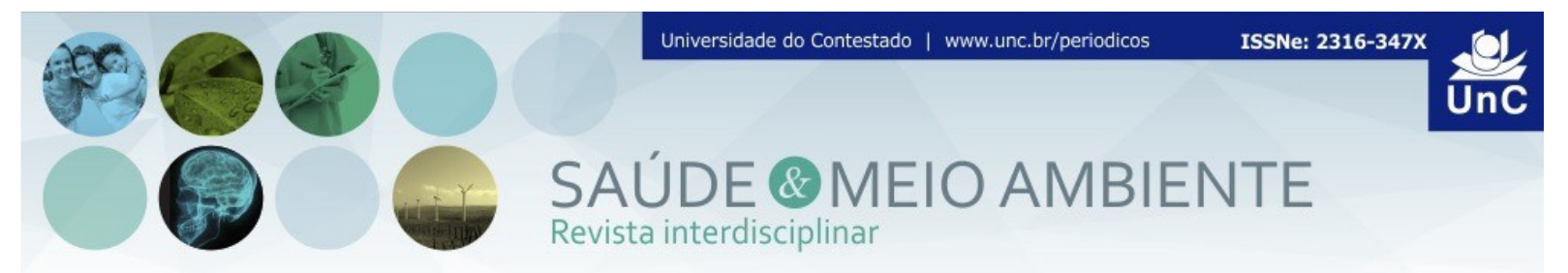

\title{
TEMÁTICA AMBIENTAL NA PRÁTICA DOS ENFERMEIROS ATUANTES NAS UNIDADES DE SAÚDE DA FAMÍLIA
}

\author{
Marina da Silva Junqueira ${ }^{1}$ \\ Juliana Tavares da Silva ${ }^{2}$ \\ Natálya Fernanda Freitas Andrade ${ }^{3}$
}

\begin{abstract}
RESUMO
Objetivo: Investigar a incorporação da temática ambiental na prática dos Enfermeiros. Metodologia: Trata-se de uma pesquisa do tipo quantitativa, de caráter descritivo onde foi aplicado um questionário com seis enfermeiros das Unidades de Saúde da Família (USF) dos municípios de Olinda e Recife- PE entre outubro e novembro de 2017. Resultados: Sobre o conhecimento da Portaria 2.488/2011, 50\% dos profissionais entrevistados $(n=3)$ informaram conhecimento. $O$ saneamento básico está presente em $67 \%(n=4)$ das USF, onde $83 \%(n=5)$ das unidades apresentam canal nas proximidades e casos de doenças veiculadas por elementos do meio ambiente circundante. Conclusão: $O$ papel do Enfermeiro tem destaque no apoio à saúde da população, embora deva englobar ações mais abrangentes voltadas para a interseção com o meio ambiente através de práticas educativas junto à comunidade, ampliando a prevenção de doenças e agravos.
\end{abstract}

Palavras-Chave: Enfermagem. Saúde ambiental. Educação em Saúde.

\section{ENVIRONMENTAL THEMATICS IN THE PRACTICE OF NURSING NURSES IN THE FAMILY HEALTH UNITS}

\begin{abstract}
Objective: To investigate the incorporation of the environmental theme in Nurses' practice. Methodology: This is a qualitative-quantitative research, with a descriptive character where a questionnaire was applied with six nurses from the Family Health Units (USF) of the municipalities of Olinda and Recife-PE between October and November 2017. Results: Regarding the knowledge of the Ordinance 2,488 / 2011, $50 \%$ of the interviewed $(n=3)$ reported knowledge. Basic sanitation is present in $67 \%$ $(n=4)$ of the USF, where $83 \%(n=5)$ of the units present a nearby canal and cases of diseases carried by elements of the surrounding environment. Conclusion: The role of the nurse has a prominent role in supporting the health of the population, although

\footnotetext{
${ }^{1}$ Graduada em Enfermagem. Centro Universitário Maurício de Nassau (UNINASSAU). Recife.

Pernambuco. Brasil. E-mail: marinajunqueirasdt@hotmail.com

${ }^{2}$ Mestre em Biodiversidade pela Universidad de Valencia. Centro Universitário Maurício de Nassau

(UNINASSAU). Recife. Pernambuco. Brasil. E-mail: juliana2tavares@hotmail.com

${ }^{3}$ Graduada em Enfermagem. Centro Universitário Maurício de Nassau (UNINASSAU). Recife.

Pernambuco. Brasil. E-mail: natalianadrade@hotmail.com
} 
it should encompass more comprehensive actions aimed at the intersection with the environment through educational practices in the community, increasing the prevention of diseases and injuries.

Keywords: Nursing. Environmental Health. Health Education.

\section{INTRODUÇÃO}

As alterações ambientais que provocam destruição de ecossistemas vêm modificando o contexto natural e intensificando o processo de saúde-doença. Observa-se nas comunidades urbanizadas esta relação íntima da saúde da população e as condições de seu entorno, desta forma vê-se que o meio onde se vive não é apenas uma paisagem sem interação, sem trocas, sem refletir as atitudes que trazem benefícios e malefícios, influenciando direta e indiretamente na qualidade da saúde ${ }^{1}$. Estas alterações no ambiente urbanizado ocorrem de ações antrópicas, o que resulta em diversos problemas para a qualidade de vida da população. É necessária uma discussão constante entre os diversos atores sociais e setores sobre os riscos ambientais e seus efeitos sobre a saúde, visto que efeitos negativos tornam-se um problema de saúde coletiva. A existência da relação entre saúde e meio ambiente pressupõe uma ação interdisciplinar que priorize o desenvolvimento de atividades de educação ambiental na atenção primária à saúde. Neste nível de atenção, o profissional Enfermeiro é um dos responsáveis em realizar educação em saúde voltada para as questões primordiais do indivíduo com o seu entorno, família e coletividade ${ }^{2}$. A influência direta e indireta das condições ambientais de uma área urbana no processo de saúde-doença, apesar dos avanços relacionados com a saúde pública, como a queda de mortalidade, trazem um novo desafio para ser enfrentado diante de aspectos populacionais, como crescimento, envelhecimento e aumento da expectativa de vida global, antes que as previsões de perda de qualidade ambiental e consequente perda da qualidade de vida se confirmem irreversíveis. Em razão da amplitude desta questão, devem ser adotados conceitos que reafirmem a importância do papel dos profissionais de saúde diante das questões ambientais, visando uma maior atenção a promoção à saúde promovendo discussões sobre esta temática e que supere o modelo atual ${ }^{3}$. Salienta-se a relevância dos diversos trabalhadores da saúde, dentre eles o Enfermeiro, que é responsável pela maior parte da prestação da assistência ao cuidado, em integrar saberes ecológicos em suas atividades teórico/práticas, ou seja, tomar atitudes locais, pensando nas repercussões globais ${ }^{4}$. Neste enfoque, a apropriação do conceito de sustentabilidade resulta em descobrir como as pessoas podem contribuir para o bem-estar coletivo assumindo a responsabilidade própria em proporcionar condições para que o planeta continue mantendo os recursos suficientes para a vida de todos, em toda parte demonstrando o amadurecimento da visão ambiental ${ }^{5}$. Associando a saúde à qualidade ambiental, as decisões econômicas e políticas com reflexos sociais e no âmbito da vida pessoal da população precisam ser decisivas para as alterações que devem ocorrer no contexto da vida em comunidade ${ }^{6-7}$. 
Desta forma, a amplitude sustentável na manutenção da condição de saúde de uma população implica em políticas de cobertura universal por meio de sistemas de saúde integrais, equitativos e de qualidade - necessariamente não sendo reduzida aos seus componentes de assistência médica aos indivíduos doentes ${ }^{8}$. No integral é onde precisamente se encontra a dimensão ambiental do elemento saúde coletiva do sistema de saúde. Esta dimensão sugere, entre outros, o comprometimento e efetivação por instituições públicas e empresas privadas de um conjunto de ações sobre o meio ambiente que impactam diretamente a saúde humana: saneamento básico, abastecimento de água potável, destinação adequada do lixo, controle sobre os fatores de risco presentes nos processos produtivos urbanos e rurais ${ }^{5,8,9}$

Vê-se que a atuação do profissional Enfermeiro, assim como os demais profissionais na atenção primária à saúde, é crucial para agregar a compreensão da intimidade dos aspectos ambientais com a saúde na rotina de uma população, conscientizando sobre os riscos ambientais, entendendo-os como possíveis geradores de doenças. A prática cotidiana de prestação de cuidado faz do Enfermeiro, seja pelo embasamento teórico oferecido durante a academia ou pela experiência prática que adquire com o passar dos anos de atuação na atenção primária à saúde, um importante esclarecedor de situações ambientais à população ${ }^{10}$. Como estratégia para atenção primária, o Enfermeiro deve desempenhar o papel de educador ambiental informal, disseminando informações para que as pessoas se apropriem do conhecimento sobre as relações ambientais ecológicas e a sociedade, assim influenciando definitivamente a saúde local, com destaque para a prevenção de doenças e minimização de fatores deletérios à saúde, incentivando a responsabilidade de cada cidadão na luta por um meio ambiente mais equilibrado, garantindo uma melhor qualidade de vida com menos ricos ambientais ${ }^{1,11}$. Assumindo este papel indispensável à boa atuação profissional, a disponibilidade e interesse para assumir uma postura que supere práticas assistencialistas garantirão práticas transdisciplinares, podendo fazer parte de uma equipe sensível e atenta às questões ambientais ${ }^{1}$.

O objetivo deste estudo é de investigar a incorporação da temática ambiental na prática dos enfermeiros, onde se buscou especificamente levantar informações sobre os casos mais frequentes de doenças relacionadas aos aspectos ambientais e analisar o papel do enfermeiro no âmbito ambiental. A relevância do enfermeiro na educação em saúde ambiental não é prevista na legislação, embora a formação voltada para os processos de doença, prevenção e recuperação da saúde são intrínsecos ao seu papel e habitualmente são estes profissionais que encaram o desafio de educar para a saúde, se tornando um importante agente educador ${ }^{12}$. Desta forma, a saúde sendo indissociável das condições ambientais, o significado da atuação do Enfermeiro nas transformações de concepções, crenças e atitudes da população é diretamente proporcional ao seu preparo em desenvolvimento de competências para atuar junto à realidade local. Os resultados desta pesquisa indicam elementos que fazem parte da realidade vivida pelo binômio profissional de saúde/população num contexto ambiental. São resultados iniciais, porém relevantes, que devem ser aprofundados em estudos posteriores por já demonstrarem sua inserção na qualidade de vida da população. 


\section{METODOLOGIA}

Esta pesquisa foi realizada após aprovação no Comitê de Ética em Pesquisa com Seres Humanos - CEP do Centro Universitário Maurício de Nassau, Recife, sob parecer consubstanciado número 2.284.210. Trata-se de uma pesquisa exploratória descritiva, do tipo quantitativa. Os dados foram coletados entre outubro e novembro de 2017. Os instrumentos de coleta de dados utilizados foram entrevista e questionários semiestruturados, sendo os procedimentos direcionados para o levantamento de dados com o uso dos instrumentos. A amostra foi composta por três USF (Unidades de Saúde da Família) localizadas na cidade do Recife nos Distritos Sanitários II e III e três USF na Regional I da cidade de Olinda. A amostra das áreas de coleta foi determinada por conveniência e foram realizadas coletas com um universo amostral de seis profissionais, todos os participantes assinaram o Termo de Consentimento Livre e Esclarecido - TCLE. Para o tratamento dos dados quantitativos foi utilizado o programa Excel na plataforma Windows. Para análise dos dados foram utilizadas as orientações do Ministério da Saúde para atuação do profissional de Enfermagem no Programa de Saúde da Família ${ }^{13}$.

\section{RESULTADOS}

Um Enfermeiro foi entrevistado em cada USF e, entre estes, $50 \%(n=3)$ se formaram na UFPE e $50 \%$ na UPE $(n=3)$ (Gráfico 1). Como estratégia de formação continuada, todos têm curso de especialização, distribuídos principalmente na área de Saúde da Família (Gráfico 2).

Gráfico 1 - Formação Acadêmica

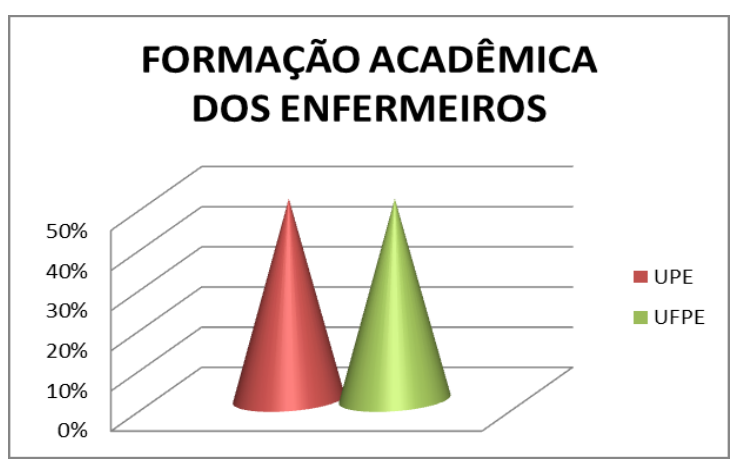

Gráfico 2 - Formação continuada

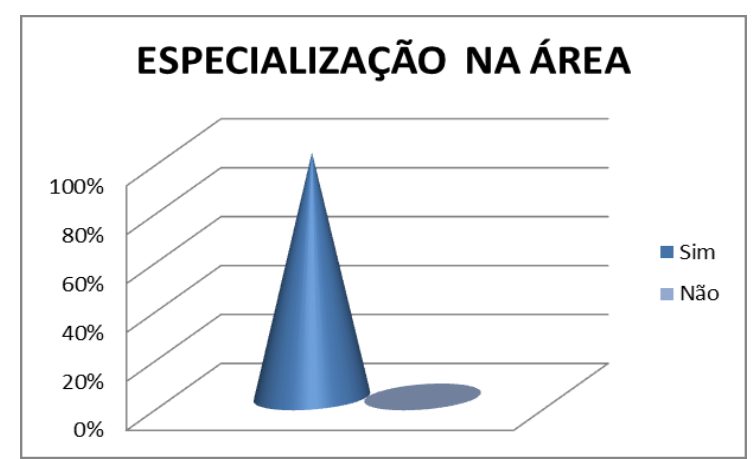

Os Enfermeiros entrevistados foram questionados sobre o conhecimento da Portaria 648 (revogada pela Portaria 2.488), onde 50\% (n=3) informaram conhecimento e $50 \%(n=3)$ informaram desconhecimento (Gráfico 3 ). Sobre o tempo de atuação na Enfermagem, os entrevistados apontaram uma diversidade que 
abrange entre 7 e 32 anos de atividade profissional, sendo um formado há 7 anos, um há 15 anos, um há 20 anos, um há 23 anos, um há 27 anos e um há 32 anos.

Gráfico 3 - Conhecimento da Portaria

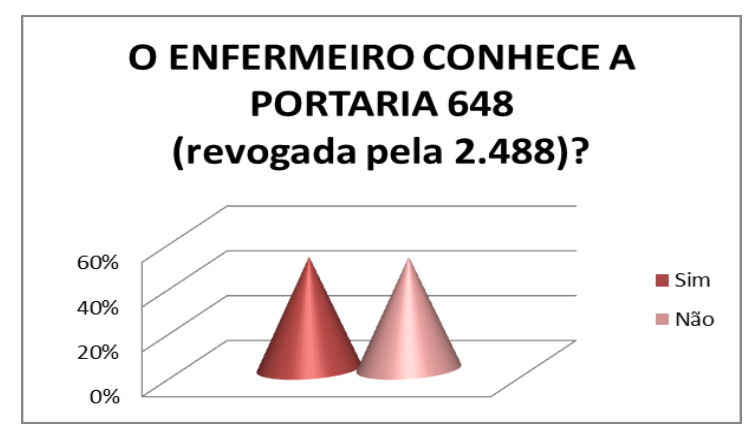

Gráfico 4 - Tempo de Formação

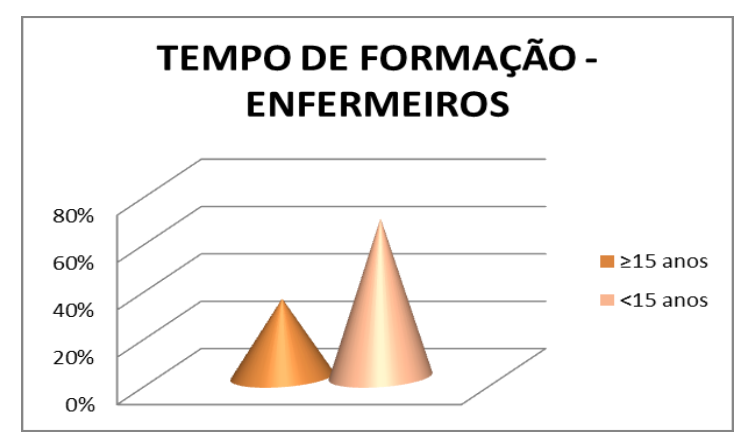

Abordando o atendimento à população na Unidade de Saúde da Família, em 2016 os casos de leptospirose, cólera, teníase/cisticercose, infestação por pulgas, hepatite $\mathrm{A}$, salmonelose e filariose foram descritos como inexistentes, tanto quanto os de toxoplasmose, leptospirose, cólera, teníase/cisticercose, infestação por pulgas, hepatite A, salmonelose e filariose em 2017. O caso descrito apenas em 2016 foi de toxoplasmose. Os descritos em 2016 e 2017 foram de arboviroses (dengue/zika/chikungunya), verminoses (Amebíase, Giardíase, Ascaridíase) e escabiose, sendo as verminoses quatro vezes mais incidentes em 2017 do que em 2016 (ver Gráficos 5 e 6). 
Gráfico 5 - Doenças em 2016

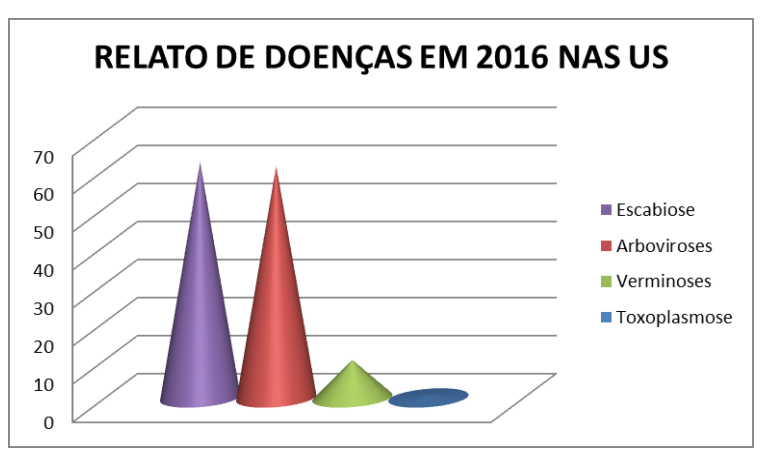

Gráfico 6 - Doenças em 2017

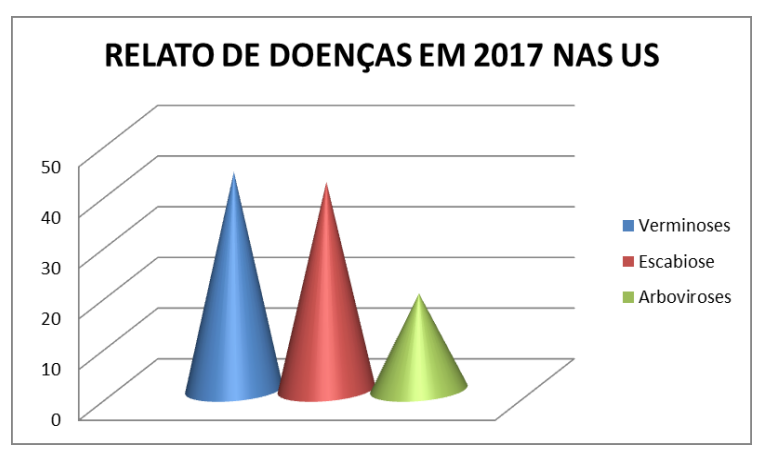

Investigando as condições ambientais que podem favorecer este quadro de doenças que se disseminam na população local foi informado que, das USF (Unidades de Saúde), 83\% ( $n=5$ ) apresentam canal nas proximidades. Estes canais são o destino do esgoto, proporcionando o convívio das pessoas com o odor forte, insetos e roedores que buscam estes ambientes com matéria em decomposição. No entanto, o lixo é coletado (83\%) e diariamente (83\%), porém apresentam muitos animais (cães e gatos) soltos nas ruas (descrito em $83 \%$ das USF pesquisadas). O saneamento básico está presente em $67 \%(n=4)$ das USF e a água é fornecida pela empresa pública de abastecimento local de água. Entre os Enfermeiros, $67 \%(n=4)$ identificam como problema ambiental o lixo ser jogado no rio e/ou a presença de canal com depósito de esgoto, ainda identificando animais soltos vivendo na rua (20\%), lixo descartado a céu aberto (20\%) e esgoto despejado a céu aberto (20\%). Quando questionados sobre a população reaproveitar a água utilizada em casa, nenhum disse que conhece esta prática (sobre estes dados, ver o Gráfico 7).

Gráfico 7 - Entorno próximo das USF

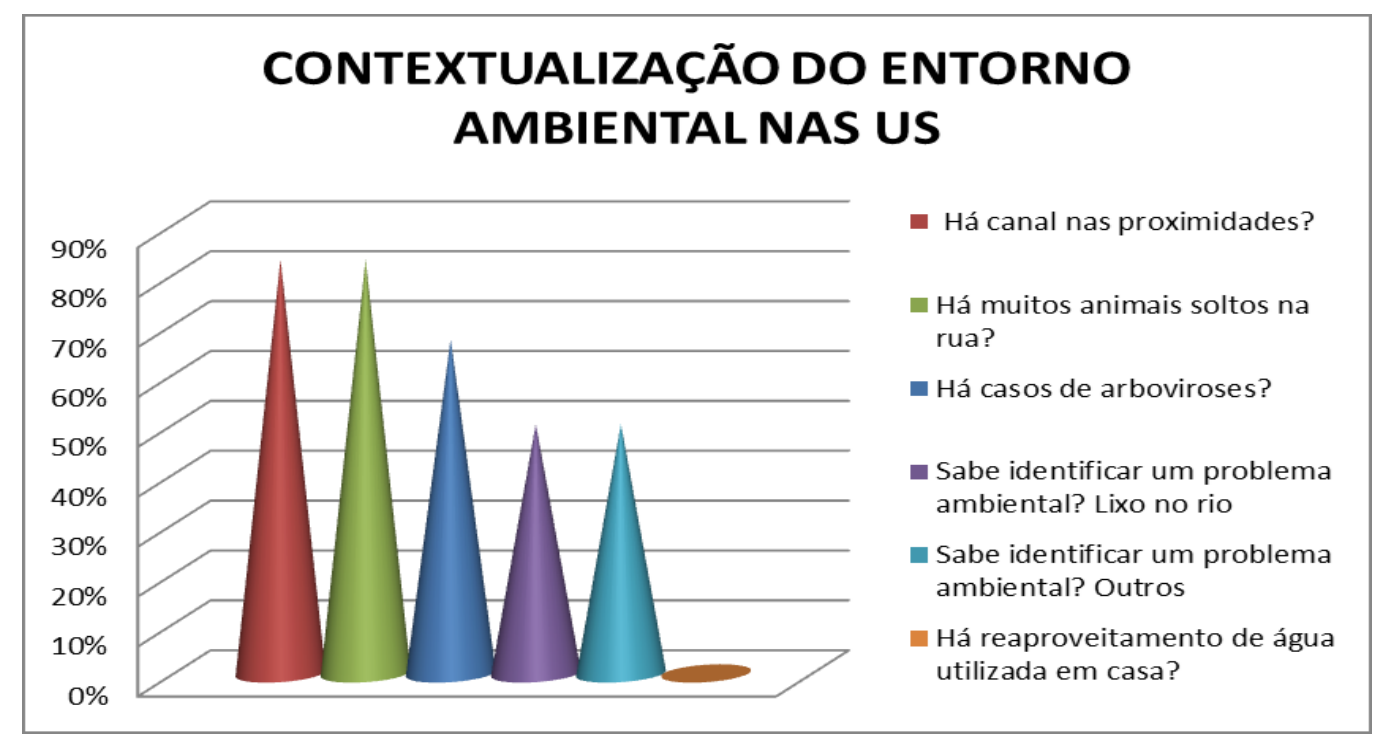


Já sobre as atividades voltadas para a área ambiental na atuação dos Enfermeiros nas USF, todos os entrevistados disseram ter interesse nesta área, embora apenas $50 \%(n=3)$ citaram reuniões e/ou palestras sobre Educação Ambiental. Em contrapartida, existe o apoio de líderes comunitários para atividades ambientais, há atividades de educação ambiental para a população e para sustentabilidade na USF $(67 \%)$. Felizmente, $83 \%(n=5)$ das USF pesquisadas indicaram que há apoio da Vigilância Ambiental voltado para a vigilância epidemiológica dos municípios pesquisados (Gráfico 8).

Gráfico 8 - Atividades ambientais nas USF

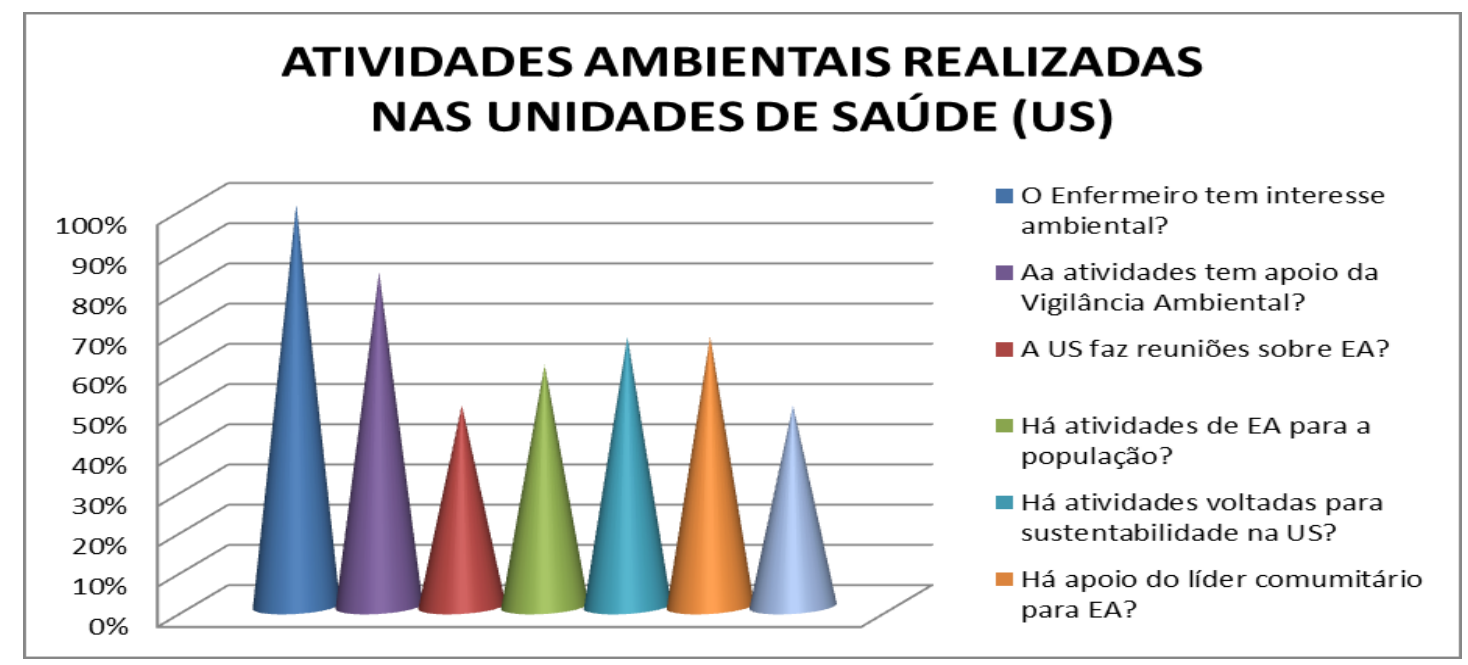

\section{DISCUSSÃO}

Os profissionais pesquisados evidenciam uma busca pela formação continuada, tendo cursos de pós-graduação realizados na área de atuação, embora o percentual da amostra que descreve conhecimento da legislação em vigor seja mediano. A Portaria 2.488, de 21 de outubro de 2011, que revogou a Portaria 648, de 28 de março de 2006, aprova a Política Nacional de Atenção Básica para o Programa Saúde da Família (PSF) e o Programa dos Agentes Comunitários de Saúde (PACS), que tem como áreas estratégicas para atuação em todo território nacional os indicadores da saúde, com objetivo de controle e/ou erradicação de doenças endêmicas e crônicas da população. Da infraestrutura necessária, consta a participação do Enfermeiro na equipe multiprofissional, onde há dois aspectos importantes: i) o processo de educação permanente dos profissionais da equipe multidisciplinar, sob responsabilidade das Secretarias Municipal e Estadual de Saúde; e ii) o processo de trabalho da equipe com, por exemplo, programação e implementação das atividades, com a priorização de solução dos problemas de saúde mais frequentes e o desenvolvimento de ações educativas que possam interferir no processo de saúde-doença da população e ampliar o controle social na defesa da 
qualidade de vida. Sendo um documento que orienta sobre a amplitude da atuação do profissional, deveria ser conhecida em detalhes por todos os profissionais ativos.

O tempo de atuação profissional que os garante rica experiência na área, apropriando-os com capacitação para realizar o que as diretrizes preconizadas pela Política Nacional de Atenção Básica (PNAB) preveem como atribuição comum a todos os profissionais da saúde: mobilizar a comunidade para desenvolver medidas de manejo ambiental e outras formas de intervenção no ambiente para o controle de vetores, assim como formação para guiar discussões e planejamentos de modo articulado e integrado com as equipes de vigilância em ações de controle vetorial. O profissional Enfermeiro tem papel fundamental nas unidades básicas de saúde, com responsabilidade em ações assistenciais e gerenciais, sendo ator indispensável na promoção da saúde orientada consistentemente para prevenir os riscos locais de danos à saúde ${ }^{14}$. Estes riscos, atualmente já evidentes na percepção dos profissionais de saúde, envolvem o meio ambiente e ao longo da história da saúde pública brasileira esteve aderida a preocupação com o saneamento básico, com a área dos resíduos sólidos, industriais e domésticos, com o saneamento rural e com os ambientes de trabalho e a saúde dos trabalhadores. Foi evidenciado que escabiose, verminoses e arboviroses são, nas USF pesquisadas, os casos mais frequentes de doenças associadas às condições ambientais, requerendo dos profissionais que atendem a população orientações para que as pessoas assumam uma postura responsável na prevenção. Desta forma, vê-se o ambiente como elemento de interação com o aparecimento de doenças e como fonte de agentes e vetores ligados à cadeia natural de doenças infecciosas ${ }^{15}$. Ao avaliar os resultados obtidos sobre essas questões, observou-se que os profissionais estão desenvolvendo suas atividades de acordo com o que estabelece a legislação vigente, já que dos seis enfermeiros entrevistados, quatro indicaram que existe apoio da vigilância ambiental do município.

Enfermeiro que atua em Programas de Saúde da Família pode trazer importantes contribuições, especialmente, por meio da consulta de Enfermagem, envolvendo a Sistematização da Assistência de Enfermagem (SAE), e de educação em saúde voltada para o indivíduo, família e comunidade, acompanhando os hábitos e comportamentos que podem influenciar no surgimento das doenças para direcionar o planejamento do cuidado ${ }^{16}$. Também deve ser assumido pelo profissional de Enfermagem, e condições para tal devem ser proporcionadas pelo poder público, a capacitação de comunidades por meio de ações pedagógicas a partir da vida cotidiana, das necessidades e dos interesses pessoais e coletivos que envolvem a saúde ambiental, pois este fato é uma necessidade global. Deve-se refletir sobre a importância da abertura de um espaço de formação que propicie reflexão, problematização, crítica e articulação, apontando o comprometimento com a construção de sujeitos que incorporem posturas éticas, de solidariedade, de consciência cidadã e de compromisso social, atuando de forma responsável com o meio ambiente, tudo isso alicerçado em práticas pedagógicas efetivas para o processo de mudança9 .

O importante papel da Educação Ambiental não deve se restringir somente ao meio ambiente físico, abrangendo o contexto local em sua complexidade na relação entre a sociedade e o meio ambiente (saúde local, prevenção de doenças, gestão dos 
fatores ambientais deletérios à saúde) sendo estes atores sociais um indiscutível elemento na manutenção das condições de saúde de uma população ${ }^{11}$.

Limitações do Estudo: O estudo abrangeu a pesquisa sobre o conhecimento do enfermeiro para a sua atuação no âmbito ambiental, não incluindo a atuação clínica.

\section{CONCLUSÃO}

A assistência e o cuidado prestados pelo Enfermeiro à comunidade no âmbito da atenção básica têm como requisito para eficiência englobar ações ambientais. A saúde tem um caráter multidimensional. Portanto, a dedicação por parte do Enfermeiro em adotar práticas de educação em saúde ambiental, já previstas na formação profissional e na legislação vigente, é fundamental na intervenção nos problemas ambientais do entorno, com o apoio e investimento de recursos públicos que se fazem indispensáveis na prática deste ator social. Os profissionais pesquisados aplicam seus conhecimentos no atendimento à população minimizando a problemática ambiental local, principalmente das doenças mais comuns relacionadas às condições precárias de saneado, e utilizando recursos públicos que são direcionados para sua atividade. Sabendo-se que a realidade nacional é de políticas públicas ambientais que não suprem por completo as necessidades da população, a efetivação de recursos públicos para soluções ambientais definitivas fundamentadas nas questões decorrentes das relações comunidade/ambiente/saúde do entorno são necessárias para o desenvolvimento de atividades e de programas baseados na melhoria da qualidade de vida da população, por meio da prevenção de doenças e agravos relacionados às questões envolvendo o meio ambiente.

Os autores declaram que não há conflitos de interesse.

\section{REFERÊNCIAS}

1. Bruzos GAS, Kamimura HM, Rocha SA, Jorgetto TAC, Patrício KP. Meio ambiente e enfermagem: suas interfaces e inserção no ensino de graduação. Rev. Saúde soc. [Internet]. 2011 Jun [acesso em 2018 Abr 03];20(2):462-469. Disponível em: http://www.scielo.br/pdf/sausoc/v20n2/17.pdf

2. Santos DAS, Silva MS. Atuação do enfermeiro na educação ambiental e a relação com a sua formação acadêmica. Rev. Eletrônica Mestr. Educ. Ambient. [Internet]. 2014 Jul [acesso em 2018 Abr 03];31(2):127-139. Disponível em: https://periodicos.furg.br/remea/article/view/4647. 
3. Patrício KP, Oliveira TS, Ribeiro JTR, Medeiros TM, Cruvinel MCFP, Miguel MM, Pogetto MRBD, Soaresi TB, Blasque WP. Meio ambiente e saúde no Programa PETSaúde: interfaces na atenção básica. Rev. Brasileira de Educ. Médica. [Internet]. 2011 Fev [acesso em 2018 Abr 06];35(3):341-349. Disponível em http://www.scielo.br/pdf/rbem/v35n3/a07v35n3.pdf.

4. Moreschi C, Siqueira DF, Dalcin CB, Grasel JT, Backes DS. Homenagem a Florence Nightingale e compromisso com a sustentabilidade ambiental. Rev. Baiana de Enfer. [Internet]. 2011 Maio [acesso em 2018 Abr 08]; 25(2): 203-208. Disponível em: file:///C:/Users/deocl/Downloads/5260-18542-2-PB.pdf

5. Silva VPR, Aleixo DO, Neto JD, Maracajá KFB, Araújo LE. Uma medida de sustentabilidade ambiental: pegada hídrica. Rev. Bras. Eng. Agríc. Ambient. [Internet]. 2013 Jan [acesso em 2018 Abr 10]; 17(1):100-105. Disponível em: http://www.scielo.br/pdf/rbeaa/v17n1/v17n01a14.pdf

6. Beserra EP, Alves MDS. Enfermagem e saúde ambiental na escola. Acta paul. enferm. [Internet]. 2012 [acesso em 2018 Abr 11];25(5):666-672. Disponível em: http://www.scielo.br/pdf/ape/v25n5/04.pdf

7. Camponogara S, Viero CM, Erthal G, Rossato GC. Enfermagem e meio ambiente: uma revisão bibliográfica. Rev. Enferm. UFSM [Internet]. 2011 Out [acesso em 2018 Abr 03];1(3):472:480. Disponível em: file://C:/Users/deocl/Downloads/3268-17917-1PB.pdf

8. Buss PM, Machado JMH, Gallo E, Magalhães DP, Setti AFF, Netto FAF, Buss DF. Governança em saúde e ambiente para o desenvolvimento sustentável. Rev. Ciência \& Saúde Colet. [Internet]. 2012 Maio [acesso em 2018 Abr 14]:17(6):14791491. Disponível em: http://www.scielo.br/pdf/csc/v17n6/v17n6a12.pdf

9. Beserra EP, Alves MDS, Pinheiro PNC, Vieira NFC. Educação ambiental e enfermagem: uma integração necessária. Rev. Bras. Enferm. [Internet]. 2010 Out [acesso em 2018 Abr 19]: 63(5):848-852. Disponível em:

http://www.scielo.br/pdf/reben/v63n5/26.pdf

10. Santos GAC, Rosa JS, Matos ECO, Santana ME. Dengue: Prevenção, Controle e Cuidados de Enfermagem - Revisão Integrativa da Literatura 2008-2013. Rev.

Brasileira de Ciênc. da Saúde.[Internet]. 2016 [acesso em 2018 Abr 27]: 20(1):71-78. Disponível em: file:///C:/Users/deocl/Downloads/21374-61851-1-PB.pdf

11. Pereira CAR, Melo JV, Fernandes ALT. A educação ambiental como estratégia da Atenção Primária à Saúde. Rev. Brasileira de Med. Fam. Comunidade. [Internet]. 2012 Abr-Jun [acesso em 2018 Abr 01]:7(23):108-116. Disponível em:

file:///C:/Users/deocl/Downloads/293-2786-2-PB.pdf

12. Colome JS, Oliveira DLLC. Educação em saúde: por quem e para quem? A visão de estudantes de graduação em enfermagem. Texto Contexto Enferm. [Internet]. 2012 Mar [acesso em 2018 Abr 01]:21(1):177-184. Disponível em: http://www.scielo.br/pdf/tce/v21n1/a20v21n1.pdf 
13. Costa MBS, Lima CB, Oliveira CP. Atuação do enfermeiro no Programa Saúde da Família (PSF) no estado da Paraíba. Rev. Bras. Enferm. [Internet]. 2000 Dez [acesso em 2018 Abr 04]: 53:149-152. Disponível em:

http://www.scielo.br/pdf/reben/v53nspe/v53nspea25.pdf

14. Gomes LMX, Barbosa TLA, Silva CSO, Lopes JR, Leite MTS. Prática gerencial do enfermeiro na estratégia saúde da família. Rev. Trab. Educ. Saúde. [Internet]. 2015 Dez [acesso em 2018 Abr 10]:13(3):695-707. Disponível em:

https://www.redalyc.org/pdf/4067/406756978009.pdf

15. Vaz MRC, Weis AH, Costa VZ, Soares JFS, Bonow CA, Cardoso LS, Sant'Anna CF, Soares MCF, Baich ALM. Estudo com enfermeiros e médico da atenção básica à saúde: uma abordagem socioambiental. Rev. texto e contexto enferm. [Internet]. 2007 Out-Dez [acesso em 2018 Abr 01]:16(4):645-653. Disponível em: http://www.scielo.br/pdf/tce/v16n4/a08v16n4.pdf

16. Agostinho KM, Cavalcante KMH, Cavalcanti PP, Pereira DL. Doenças dermatológicas frequentes em unidade básica de saúde. Rev. cogitare enferm. [Internet]. 2013 Out-Dez [acesso em 2018 Abr 04];18(4):715-721. Disponível em: file://C:/Users/deocl/Downloads/34927-128321-1-PB.pdf

Artigo recebido em: 27/12/2018

Artigo aprovado em: 24/04/2019

Artigo publicado em: 27/05/2019 